TAP CHÍ DẦ KHÍ

Số 12 - 2020, trang 17 - 29

ISSN 2615-9902

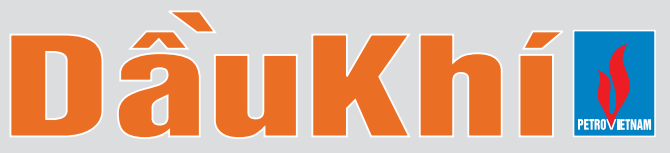

\title{
CHUYỂN ĐỔI SỐ TRONG THĂM DÒ KHAI THÁC DẦU KHÍ
}

\section{Nguyễn Anh Đức}

Tập đoàn Dầu khíViệt Nam

Email:ducna@pvn.vn

https://doi.org/10.47800/PVJ.2020.12-03

\section{Tóm tắt}

Chuyển đổi số mang lại cơ hội lớn cho các doanh nghiệp để tạo ra và nắm bắt giá trị. Sự phát triển các công nghệ như điện toán đám mây, truyền thông xã hội và phân tích dữ liệu lớn đang thúc đẩy các xu hướng mang lại tiềm năng to lớn cho ngành dầu khí.

Bài báo tập trung giới thiệu các xu thế chuyển đổi số trên thế giới, hiện trạng, xu hướng chuyển đổi số ở các doanh nghiệp dầu khí nói chung và lĩnh vực thăm dò khai thác dầu khí nói riêng. Bài báo cũng đưa ra một số kiến nghị cho công tác chuyển đổi số lĩnh vực thăm dò khai thác dầu khí ở Việt Nam.

Từ khóa: Chuyển đổi số, thăm dò khai thác dầu khí, xu hướng.

\section{Giới thiệu}

Chương trình chuyển đổi số trên thế giới có các nội dung khác nhau, phụ thuộc vào chiến lược phát triển kinh tế - xã hội của từng nước. Tuy nhiên, các nội dung chính gồm: i) Chuyển đổi số nền kinh tế (kinh tế số); ii) Chuyển đổi số xã hội (xã hội số); iii) Chuyển đổi số trong một số ngành trọng điểm; iv) Chuyển đổi số trong cơ quan Chính phủ (Chính phủ số); v) Phát triển hạ tầng số (phát triển mạng di động thế hệ mới, kết nối cáp quang đến các gia đình, doanh nghiệp, cung cấp wifi miễn phí tại khu vực công cộng, phát triển điện toán đám mây, hạ tầng loT, big data...); vi) Phát triển lực lượng lao động có kỹ năng số; vii) Đẩy mạnh công tác nghiên cứu công nghệ số mới; viii) Xây dựng môi trường pháp lý để bảo đảm môi trường an toàn, tin cậy, thúc đẩy chuyển đổi số [1, 2].

Theo khảo sát của DXC.Technology và Economist Intelligence Unit, các doanh nghiệp toàn cầu sẽ tăng đầu tư vào công nghệ kỹ thuật số trong thời gian tới, vì các khoản đầu tư này gắn trực tiếp với kết quả kinh doanh. $68 \%$ cho biết lợi nhuận hàng năm của tổ chức đã tăng lên trong 3 năm qua nhờ chiến lược kỹ thuật số, $74 \%$ kỳ vọng lợi nhuận sẽ tăng trong 3 năm tới [3]. Các ngành công nghiệp nói chung và ngành công nghiệp dầu khí nói riêng đang thay đổi nhanh chóng nhờ tiến bộ công nghệ. Kể từ cuộc cách mạng công nghiệp, dầu khí đã đóng vai trò

Ngày nhận bài: 12/8/2020. Ngày phản biện đánh giá và sửa chữa: 12/8 - 16/9/2020. Ngày bài báo được duyệt đăng: 15/12/2020. quan trọng trong sự chuyển đổi kinh tế của thế giới. Ngày nay, dầu khí có cơ hội tiếp tục khẳng định vai trò quan trọng thông qua số hóa.

Ngành dầu khí không còn xa lạ với dữ liệu lớn, đổi mới công nghệ và kỹ thuật số. Ngay từ những năm 1980, các doanh nghiệp dầu khí bắt đầu áp dụng các công nghệ kỹ thuật số, tập trung vào việc đánh giá tiềm năng dầu khí và khả năng khai thác, cải thiện điều kiện an toàn và tăng hiệu quả hoạt động khai thác tại các mỏ dầu trên thế giới. Một làn sóng các sáng kiến áp dụng công nghệ số trong hoạt động ở các mỏ dầu đã diễn ra trong những năm 1990 và đầu thế kỷ này. Tuy nhiên, trong phần lớn thập kỷ này, ngành công nghiệp dầu khí đã không tận dụng hết các cơ hội có được từ việc sử dụng dữ liệu và công nghệ. Một giàn khoan dầu có thể tạo ra hàng terabyte dữ liệu mỗi ngày, nhưng chỉ có tỷ lệ nhỏ trong số đó được sử dụng để ra quyết định. Khi các ngành công nghiệp khác đã cách mạng hóa mô hình kinh doanh và vận hành thông qua ứng dụng toàn diện các công nghệ kỹ thuật số, cơ hội để ngành dầu khí thúc đẩy tác động chuyển đổi của số hóa đã trở nên rõ ràng hơn.

Khi giá và nhu cầu dầu đang giảm, đại dịch Covid-19 càng làm cho tình hình trầm trọng hơn, các thách thức dài hạn như chương trình công tác, ngân sách bị thay đổi cũng như biến đổi khí hậu đang “đè nặng" lên ngành công nghiệp dầu khí. Các doanh nghiệp dầu khí có nhiều sức ép cũng như cơ hội để nâng cao hiệu quả và giảm chi phí sản xuất. Thông qua việc áp dụng nhiêu hơn các nền tảng và ứng dụng kỹ thuật số, cùng với dữ liệu khai thác được tạo 
ra từ các cơ sở hạ tầng hiện có, các doanh nghiệp dầu khí sẽ có cơ hội tốt hơn để vượt qua những thách thức hiện tại và kích hoạt khả năng hoạt động từ xa, giúp ngành dầu khí tiếp tục phát triển.

Theo đánh giá của Chương trình "Sáng kiến chuyển đổi kỹ thuật số" tại Diễn đàn kinh tế thế giới 2017, các sáng kiến chuyển đổi số có thể đem lại 1,6 nghìn tỷ USD cho công nghiệp dầu khí thế giới, trong đó riêng lĩnh vực thăm dò khai thác dầu khí là 600 tỷ USD [4].

So với các lĩnh vực khác, cách tiếp cận chuyển đổi kỹ thuật số của ngành dầu khí mang tính tiến hóa hơn là mang tính cách mạng. Tuy nhiên, sự phát triển các công nghệ như điện toán đám mây, truyền thông xã hội và dữ liệu lớn và phân tích đang thúc đẩy các xu hướng mang lại tiềm năng to lớn cho ngành dầu khí. Điện toán đám mây có thể cải thiện sự linh hoạt trong kinh doanh. Dữ liệu lớn và phân tích dữ liệu lớn có thể hỗ trợ các doanh nghiệp phân tích số lượng lớn dữ liệu có cấu trúc và không cấu trúc từ các nguồn khác nhau và tạo ra thông tin chi tiết theo thời gian thực. Công nghệ di động có thể tạo ra các phương thức kinh doanh mới, trong khi các kênh truyền thông xã hội giúp tăng cường mối quan hệ với khách hàng bằng cách thực hiện các kết nối này nhanh chóng, trực tiếp và giá rẻ. Chi phí cảm biến giảm và sự xuất hiện của Internet vạn vật công nghiệp (Industrial Internet of Things - IloT) sẽ làm tăng đáng kể khối lượng dữ liệu mà các doanh nghiệp có thể truy cập. Kết hợp các công nghệ này theo cách sáng tạo có thể làm tăng khả năng theo cấp số nhân, vượt xa hiệu quả so với nếu chỉ triển khai riêng biệt. Ngoài việc cải thiện hiệu quả, số hóa có thể cho phép các doanh nghiệp tiếp cận với khách hàng tốt hơn. Dữ liệu lớn và phân tích lớn, IloT và thiết bị di động đang nổi lên như chủ đề kỹ thuật số hàng đầu cho các doanh nghiệp dầu khí.

\section{- Dữ liệu lớn và phân tích dữ liệu lớn}

Cảm biến giá rẻ, khả năng kết nối mở rộng và tốc độ tính toán đang thúc đẩy sự gia tăng nhanh chóng lượng dữ liệu thu thập bởi các doanh nghiệp dầu khí. Giàn khoan ngoài khơi hiện đại có khoảng 80.000 cảm biến, được dự báo sẽ tạo ra khoảng 15 petabyte (15 triệu gigabyte) dữ liệu trong suốt vòng đời [5]. Dữ liệu lớn và phân tích dữ liệu lớn sẽ giúp các doanh nghiệp điều hướng lượng dữ liệu khổng lồ này. Khoảng $36 \%$ các doanh nghiệp dầu khí đã đầu tư vào dữ liệu lớn và phân tích dữ liệu. Tuy nhiên, chỉ có $13 \%$ sử dụng thông tin chi tiết từ công nghệ này để thúc đẩy cách tiếp cận của doanh nghiệp đối với thị trường và các đối thủ cạnh tranh [6]. Sự khác biệt đó cho thấy các doanh nghiệp này không phải lúc nào cũng nhúng dữ liệu lớn và phân tích hoàn toàn trong hệ thống, mà chỉ đang áp dụng từng phần công nghệ này. Triển khai toàn diện có thể tác động lớn đến năng suất và điều hành.

\section{- Internet vạn vật công nghiệp}

IloT (một ứng dụng của loT), là một "hệ thống liên kết với nhau gồm các thiết bị máy tính, máy móc cơ khí, các máy móc kỹ thuật số, các vật thể hoặc con người được cung cấp các định danh duy nhất và khả năng truyền dữ liệu qua mạng mà không cần tương tác giữa người với người, người với máy tính" [7]. Trong quá trình phát triển từ sự hội tụ của các công nghệ khác nhau, lloT đã phá vỡ bức tường giữa công nghệ vận hành (OT) và công nghệ thông tin. Điều này có nghĩa là dữ liệu do máy tạo ra không có cấu trúc có thể được phân tích để hiểu rõ hơn về cơ chế cải tiến trong thiết kế và điều hành, làm cho hệ thống thông minh hơn, ra quyết định nhanh hơn. IloT cũng cho phép giao tiếp giữa máy với máy (machine to machine communication).

Đối với lĩnh vực thượng nguồn (thăm dò khai thác dầu khí), lloT có thể giúp tối ưu hóa bằng cách cung cấp những hiểu biết mới về hoạt động điều hành thông qua việc phân tích các bộ dữ liệu vận hành khác nhau (như thông số khoan) và dữ liệu nhiều chuyên môn khác nhau (như mô hình địa chất). Các doanh nghiệp trung nguồn như vận tải, đường ống và bể chứa có thêm cơ hội thương mại mới - được hưởng lợi từ việc xây dựng cơ sở hạ tầng có dữ liệu hỗ trợ. Lĩnh vực hạ nguồn (các doanh nghiệp lọc hóa dầu và bán lẻ sản phẩm dầu mỏ) có thể thấy tiềm năng trong các cơ hội doanh thu mới, từ việc mở rộng tầm nhìn của chuỗi cung ứng và hướng tới mục tiêu người tiêu dùng kỹ thuật số với các hình thức tiếp thị, kết nối khách hàng mới.

\section{- Thiết bị di động}

Các doanh nghiệp dầu khí đã đầu tư tích hợp đầy đủ các thiết bị di động vào hoạt động hàng ngày để cải tiến quy trình công việc từ giao tiếp, làm việc nhóm tốt hơn, tăng năng suất lao động và ghi lại dữ liệu thực địa tốt hơn. Công nghệ di động cũng cho phép giám sát dữ liệu thời gian thực thông qua phần mềm chuyên dụng trên điện thoại thông minh và có thể có tác động tích cực đến sức khỏe, an toàn và môi trường (HSE). Các doanh nghiệp đã cải thiện sự an toàn của nhân viên bằng cách sử dụng tọa độ GPS trên điện thoại thông minh để theo dõi công nhân trong các tình huống nguy hiểm. Triển khai các ứng dụng di động kết hợp với thẻ nhận dạng tần số vô tuyến để 


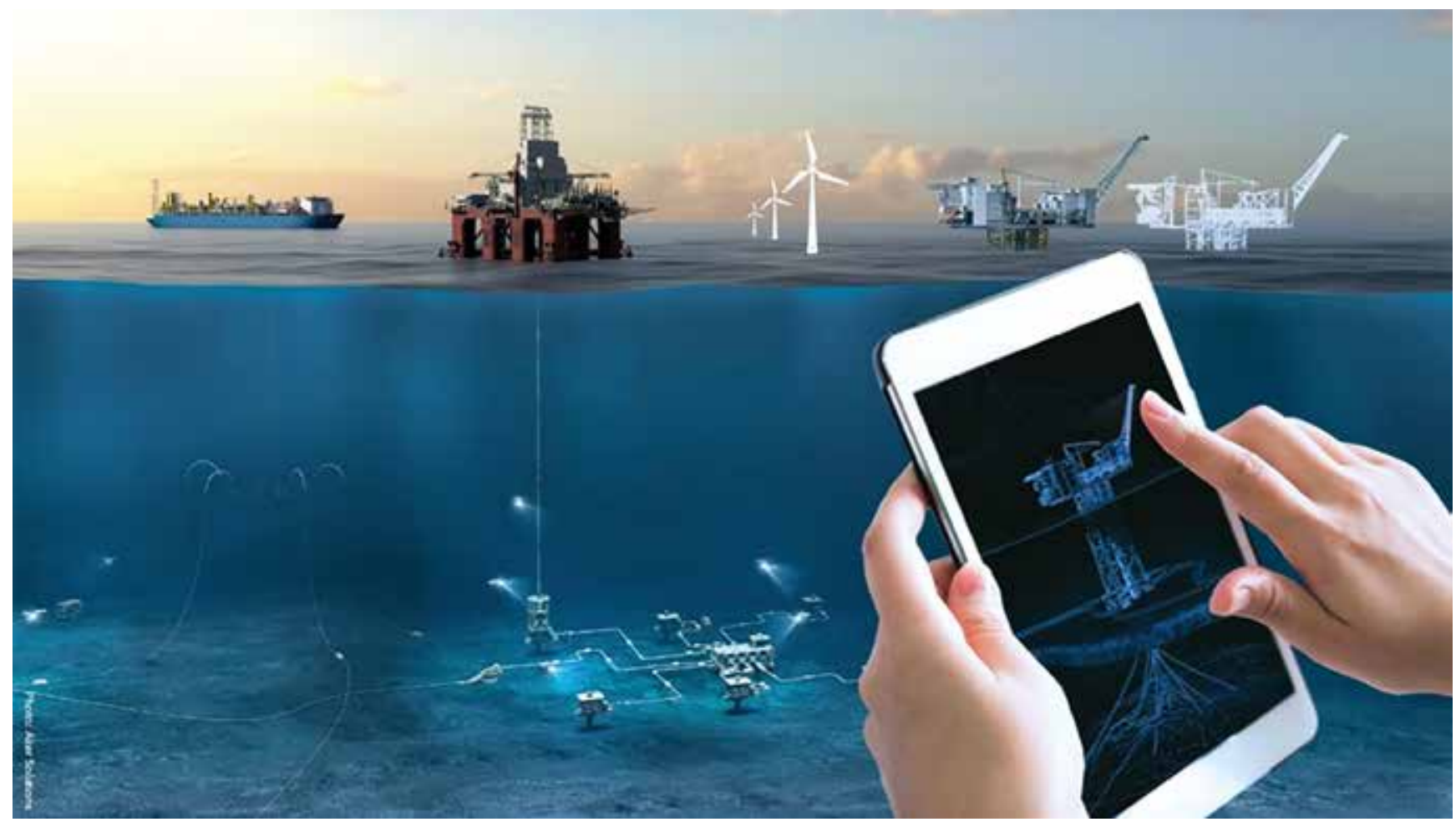

Hình 1. Thiết bị di động ngày càng được sử dụng rộng rãi trong thăm dò khai thác dầu khí

quan sát được chuyển động của con người và các trang, thiết bị.

\section{Chuyển đổi số trong lĩnh vực thăm dò khai thác dầu khí}

\subsection{Xu thế chuyển đổi số trong thăm dò khai thác dầu} khí trên thế giới

Hoạt động thăm dò khai thác dầu khí có môi trường làm việc với dữ liệu lớn (big data), với các đặc điểm như sau: i) Khối lượng lớn, từ nhiều nguồn khác nhau, tài liệu ở các dạng khác nhau như dạng mô tả, dạng số, dạng bản vẽ...; ii) Nhiều quá trình sinh dữ liệu trung gian như thu thập/khảo sát, tiền xử lý, xử lý, phân tích...; iii) Nhu cầu sử dụng tổng hợp các loại tài liệu cao (sử dụng kết hợp các loại tài liệu: địa chấn, địa vật lý, địa chất...); iv) Yêu cầu chuẩn dữ liệu của các phần mềm chuyên dụng cao, phức tạp; v) Giá trị các loại dữ liệu lớn, nhu cầu tái sử dụng dữ liệu cao.

Theo phân tích, đánh giá các lĩnh vực hứa hẹn nhất cho công tác chuyển đổi số trong thăm dò khai thác dầu khí gồm [8,9]:

- Thăm dò:

+ Cơ sở dữ liệu thăm dò khai thác (E\&P data lake);

+ Tích hợp dữ liệu và chu trình (Data and workflow integration);
+ Minh giải tự động (Automated interpretation);

+ Đánh giá vỉa chứa (Reservoir characterization);

+ Quản lý diện tích hợp đồng tiên đoán (Predictive lease management);

+ Khảo sát giếng thông minh (Downhole intelligence);

+ Địa vật lý ảo (Virtual geophysics);

+ Mô hình vỉa chứa thời gian thực (Realtime reservoir model).

- Phát triển mỏ:

+ Giàn khoan số (Digital platform);

+ Chuẩn hóa và thiết kếtheo module(Standardization and modular design);

+ Phân tích sâu tài liệu địa chấn (Deep learning for seismic);

+ Tìm kiếm nhận thức (Cognitive search);

+ Hợp tác ra quyết định (Collaborative decision making);

+ Khảo sát, đánh giá thiết bị (Surveillance and inspection).

- Khoan và hoàn thiện giếng: 
+ Tự động hóa công tác khoan (Drilling automation);

+ Tối ưu hóa công tác khoan (Drilling optimization);

+ Khoan có định hướng áp dụng trí tuệ nhân tạo (Al driven geo-steering);

+ Tối ưu hóa công tác khoan thời gian thực (Realtime drilling optimization);

+ Hoàn thiện giếng thông minh (Intelligent completions);

+ Bảo trì giàn khoan tiên đoán (Predictive drill rig maintenance).

- Khai thác:

+ Quản lý khai thác thời gian thực (Realtime production management);

+ Tối ưu khai thác mỏ (Field production optimization);

+ Tối ưu bơm ép (Artificial lift optimization);

+ Điều hành khai thác tích hợp (Integrated production operations);

+ Tự động hóa mỏ (Automated field tickets);

+ Hiệu quả của tài sản mỏ (Asset performance);

+ Mô phỏng, giám sát và kiểm soát tài sản mỏ - Bản sao số (Asset simulation, Monitoring, and Control - Digital Twin);

+ Bảo trì tiên đoán (Predictive maintenance).

- Điều hành từ xa thông minh (Intelligent remote operations) trong các hoạt động thăm dò khai thác:

+ Điều hành không người và robot (Unmanned operations and robots);

+ Kết nối các công nhân (Connected oil workers).

\subsection{Chuyển đổi số ở một số doanh nghiệp dâu khí trên thế giới}

\subsubsection{Equinor}

Tầm nhìn kỹ thuật số của Equinor được xác định với chiến lược chung là "luôn an toàn, giá trị cao, carbon thấp" với các mục tiêu: i) Cung cấp dữ liệu mọi lúc, mọi nơi để đưa ra quyết định tốt hơn, nhanh hơn; ii) Phát triển năng lực kỹ thuật số để trở thành người dẫn đầu; iii) Dự báo và ngăn ngừa sự cố an toàn và an ninh để đảm bảo an toàn cho người lao động và hoạt động của doanh nghiệp; iv) Robot hóa và điều khiển từ xa làm cho công việc thuận tiện hơn, giảm các công việc lặp đi lặp lại hàng ngày của con người [10].
Equinor cho rằng số hóa tạo ra giá trị và xem việc số hóa là hoàn toàn cần thiết để cạnh tranh trong thời gian tới. Equinor đang thiết lập 1 trung tâm kỹ thuật số xuất sắc (Digital Centre of Excellence) và đưa ra lộ trình với 7 chương trình cụ thể. Kỹ thuật số hóa sẽ giúp cải thiện sự an toàn, bảo mật và hiệu quả các hoạt động của Equinor. Năm 2020, Equinor dự kiến đầu tư 1 - 2 tỷ NOK vào các công nghệ kỹ thuật số mới. Với mục tiêu trở thành doanh nghiệp hàng đầu về kỹ thuật số toàn cầu trong các lĩnh vực cốt lõi, Equinor đang đẩy mạnh các nỗ lực để nắm bắt các cơ hội do sự phát triển nhanh chóng trong các công nghệ kỹ thuật số.

Equinor thiết lập lộ trình số hóa với 7 chương trình trong quy trình số hóa [11]:

- An toàn, an ninh và phát triển bền vững kỹ thuật số: Sử dụng dữ liệu để giảm rủi ro an toàn, cải thiện việc học hỏi từ các sự cố trong lịch sử, tăng cường bảo mật và giảm lượng khí thải carbon trong hoạt động;

- Số hóa các quá trình: Hợp lý hóa các quá trình làm việc và giảm các công việc thủ công trên toàn chuỗi giá trịi

- Phân tích tài liệu thu được trong lòng đất: Cải thiện khả năng tiếp cận dữ liệu và các công cụ phân tích dữ liệu thu được dưới lòng đất, cho phép ra quyết định tốt hơn;

- Sử dụng kết quả/tài liệu giếng khoan thế hệ mới: Tăng cường sử dụng tài liệu giếng khoan và dữ liệu thu được trong lòng đất để lập kế hoạch, phân tích thời gian thực và tăng cường tự động hóa;

- Mỏ trong tương lai: Thiết kế thông minh và lựa chọn ý tưởng phát triển (concept) bằng cách tối đa hóa việc sử dụng dữ liệu có sẵn và tích hợp các công nghệ kỹ thuật số ở các mỏ trong tương lai;

- Hoạt động điều hành dựa trên dữ liệu (data-driven operations): Sử dụng dữ liệu để tối đa hóa giá trị tài sản thông qua tối ưu hóa khai thác và cải tiến quá trình bảo trì, bảo dưỡng;

- Hiểu biết sâu sắc về thương mại: Cải thiện các công cụ phân tích và khả năng tiếp cận dữ liệu trong các lĩnh vực thương mại để cho phép ra quyết định tốt hơn.

Equinor thành lập Trung tâm điều hành tích hợp (Integrated Operations Center - IOC), sử dụng kỹ thuật số hóa để nâng cao hiệu quả khai thác, hiệu quả sử dụng năng lượng, an toàn và giảm khí thải trên các mỏ mà Equinor điều hành trên thềm lục địa [12]. IOC chủ động thu thập các nguồn lực thuộc các lĩnh vực, tích hợp, trực quan hóa và phân tích dữ liệu tổng hợp, cung cấp cho bộ 
phận điều hành trên đất liền và ngoài biển giúp đưa ra quyết định nhanh hơn với mức độ tin cậy cao hơn. Equinor sử dụng hơn 100.000 cảm biến để gửi khối lượng khổng lồ dữ liệu từ các giàn khai thác ngoài khơi trên thềm lục địa $\mathrm{Na}$ Uy đến các trung tâm hỗ trợ trên bờ. Equinor có tham vọng rất rõ ràng: $I O C$ sẽ góp phần tăng giá trị thêm hơn 15 tỷ NOK từ năm 2020 đến năm 2025. Đến năm 2021, tất cả các mỏ của Equinor trên thềm lục địa Na Uy sẽ được hỗ trợ trực tiếp từ đất liền.

Equinor thành lập Trung tâm điều hành địa chất (Geo Operations Centre - GOC) với nhiệm vụ giám sát và quản lý công tác khoan giếng ngoài khơi 24/7 bởi các chuyên gia, đảm bảo công tác khoan hiệu quả hơn, giảm chi phí và tăng mức độ an toàn. Trước đây, các công việc này chỉ được thực hiện độc lập trên biển hoặc tại các văn phòng. GOC nhận khối lượng dữ liệu khổng lồ trong khi khoan từ nhiều cảm biến đặt trong thiết bị nằm sâu dưới lòng đất. Việc điều hành tất cả các mỏ trên thềm lục địa Na Uy sẽ được chuyển dần dần cho $\mathrm{GOC}$, ngoại trừ các mỏ có nhiệt độ cao, áp suất cao (HTHP) [12].

Equinor thực hiện chương trình "Tăng tốc năng lượng Techstars" (Techstars Energy Accelerator): Equinor xác định phải áp dụng một cách tiếp cận khác cho các dự án kỹ thuật số, khác với các dự án dầu khí truyền thống. Các chuyên gia Equinor đang xem xét cách thức áp dụng từng phần phương pháp làm việc của các doanh nghiệp tham gia phát triển phần mềm.

Tầm nhìn của Equinor là trở thành một doanh nghiệp định hình năng lượng tương lai. Equinor đã tổ chức chương trình "Tăng tốc năng lượng Techstars" cho các nhà sáng tạo và doanh nhân muốn tham gia vào việc định hình tương lai của năng lượng. Chương trình đã nhận được hàng trăm đơn đăng ký từ 38 quốc gia, nhưng chỉ có 10 doanh nghiệp được chọn tham gia và đều là công ty khởi nghiệp hàng đầu trong lĩnh vực kinh doanh năng lượng, đang nghiên cứu các giải pháp về dầu khí, năng lượng tái tạo, mô hình kinh doanh mới và số hóa [13].

\subsection{2. $B P$}

Chương trình chuyển đổi số: BP đang trải qua quá trình chuyển đổi kỹ thuật số cơ bản. BP đặt mục tiêu rõ ràng cho chương trình chuyển đổi số: i) giúp cạnh tranh tốt hơn, ii) có được sự gắn kết sâu sắc hơn với nhân viên hiện tại và trong tương lai. Chương trình chuyển đổi số của BP có 3 vấn đề chính: i) các công cụ kỹ thuật số (digital tools), làm việc thông minh (agile working) và tư duy (mindset) [14].
BP thành lập Tổ chức đổi mới kỹ thuật số (Digital Innovation Organization - DIO), chuyên theo dõi, đánh giá sự phát triển công nghệ mới ảnh hưởng đến cung cầu năng lượng và đề xuất phản ứng với các công nghệ mới. DIO tập trung vào xu hướng thay đổi của công nghệ số. Các lĩnh vực trọng tâm của BP hiện nay gồm: điện toán nhận thức (cognitive computing) - hình thức tinh vi nhất của trí tuệ nhân tạo, công nghệ lưu trữ phân tán tiên tiến (advanced distributed ledger technologies) (bao gồm cả blockchain) và robot [15].

BP đang đầu tư phát triển trí tuệ nhân tạo: Từ tháng 6/2017, các công ty liên doanh của BP đã tài trợ 20 triệu USD vào Beyond Limits, doanh nghiệp hoạt động trong lĩnh vực trí tuệ nhân tạo và điện toán nhận thức. Khoản đầu tư này sẽ đẩy nhanh việc cung cấp phần mềm $\mathrm{Al}$ cấp công nghiệp, trước đây được sử dụng trong các nhiệm vụ thám hiểm không gian, để kết hợp kiến thức của con người với học máy (machine learning - ML) và cung cấp cho ngành năng lượng hiểu biết rõ hơn về điều hành, tối ưu hóa kinh doanh và tự động hóa quy trình trong các hoạt động [15]. Vào tháng 1/2019, BP đã đầu tư vào công ty khởi nghiệp công nghệ Belmont Technology (Houston) phát triển nền tảng dựa trên đám mây gọi là "Sandy" - cho phép minh giải địa chất, địa vật lý, các thông tin lịch sử và các thông tin về đá chứa, tạo ra "biểu đồ tri thức". Al liên kết thông tin trực quan, xác định các kết nối và quy trình làm việc mới, sử dụng các kết nối này để tạo ra hình ảnh về tài sản dưới lòng đất của $B P$. Khi đó, có thể sử dụng dữ liệu trong biểu đồ tri thức, kết hợp với Al sử dụng mạng trí tuệ (neural network) để thực hiện mô phỏng và minh giải kết quả [16].

BP hợp tác nghiên cứu robot: Robot đáy biển đã giúp cách mạng hóa sự hiểu biết của con người về các hoạt động dưới nước. Lượng dữ liệu rất lớn được robot truyền về gần như tức thời trong thời gian gần, các nhà khoa học có thể theo dõi môi trường biển và đại dương, đánh giá các rủi ro. BP hợp tác với Oceaneering International Inc. tiến hành thử nghiệm quy mô lớn, khảo sát các đường ống và cơ sở hạ tầng dưới đáy biển ở vịnh Mexico.

Nghiên cứu, áp dụng công nghệ số: Để giải quyết vấn đề biến đổi khí hậu toàn cầu, các doanh nghiệp dầu khí cố gắng tìm cách tăng sản lượng khai thác đồng thời giảm lượng khí thải carbon. BP đã có các khoản đầu tư lớn vào lĩnh vực xe điện, năng lượng mặt trời và năng lượng gió. Nhưng cốt lõi hơn, BP xác định phải nghiên cứu, áp dụng công nghệ số để tìm thêm nhiều mỏ dầu khí, hoặc khai thác dầu khí với chi phí thấp hơn. BP đã sử dụng công nghệ cáp quang mới, sử dụng robot trong kiểm tra các 
thiết bị ngoài khơi. Đầu tháng 1/2019, BP thông báo đã thành công khi sử dụng thiết bị địa chấn mới là Wolfspar và phát hiện thêm hơn 1 tỷ thùng dầu tại chỗ tại mỏ Thunder Horse ở vịnh Mexico [17].

BP đã có 1 dự án "bản sao kỹ thuật số" ở vịnh Mexico (digital twin project) và 1 chương trình áp dụng trí tuệ nhân tạo nhằm ngăn chặn các vấn đề xuất hiện cát trong quá trình khai thác dầu (sand production) ở khu vực Caspin. Dự án "bản sao kỹ thuật số" ở vịnh Mexico ra đời vào năm 2017. Ý tưởng là xây dựng bản sao kỹ thuật số của hạ tầng thiết bị khai thác để mô phỏng chế độ dòng chảy và tìm cách nâng cao sản lượng. Được đặt tên là $A P E X, B P$ chỉ mất 1 năm để mở rộng chương trình này cho 30 tài sản mỏ. APEX đã thực hiện một quy trình tối ưu hóa hệ thống thường yêu cầu thực hiện mất khoảng 24 giờ xuống còn 20 phút. Kết quả áp dụng APEX năm 2018 là gia tăng thêm 19.000 thùng/ngày sản lượng khai thác cơ sở của BP. Vào tháng 9/2018, BP thông báo đã triển khai một dự án "bản sao kỹ thuật số" riêng biệt cho cả 4 giàn khai thác của mình tại vịnh Mexico [17]. Chương trình được phát triển với sự hợp tác của Baker Hughes, GE để giám sát hàng ngàn cảm biến trong thời gian thực, từ bất kỳ vị trí nào. Việc này cũng được triển khai cho các hoạt động ở Oman và Angola. BP cũng đã trang bị cho gần 2.500 giếng trên khắp thế giới các cảm biến cung cấp dữ liệu cho hệ thống dựa trên điện toán đám mây có tên là Argus để đánh giá hiện trạng các giếng khoan. Bình thường nhiệm vụ quan trọng này rất tẻ nhạt và tốn thời gian, cần tới 1 tháng để tìm nạp và sắp xếp tất cả dữ liệu cần thiết. Hệ thống Argus trực quan hóa và phân tích các số liệu ngay lập tức.

$\mathrm{BP}$ chuyển hướng sang sử dụng người máy (robot) kiểm tra thiết bị ngoài khơi: Duy tu, bảo dưỡng bên ngoài của các giàn khai thác dầu khí ngoài khơi là một công việc tốn kém và nguy hiểm. Các doanh nghiệp chi hàng triệu USD/năm để sơn phủ bảo vệ chống ăn mòn, tuy nhiên, công việc đòi hỏi công nhân phải treo mình trên dây cáp trên các mặt giàn khai thác. Để giảm chi phí và hạn chế các rủi ro, $\mathrm{BP}$ đang chuyển hướng sang sử dụng robot. $\mathrm{BP}$ bắt đầu dự án này vào năm 2017, dự kiến sẽ cắt giảm một nửa chi phí kiểm tra vào năm 2025. Các robot mới có thể tham gia dịch vụ khai thác tại mỏ vào năm 2022 và cắt giảm những chi phí liên quan tới 90\% [17].

$\mathrm{BP}$ quan tâm phát triển con người trong thời kỳ phát triển mạnh các công nghệ số: Lãnh đạo $\mathrm{BP}$ xác định rằng dù công nghệ phát triển cao đến đâu, sự chuyển đổi kỹ thuật số cuối cùng vẫn là vấn đề con người. Năm 2018, BP đã tổ chức khóa đào tạo kỹ năng lãnh đạo mới cho 2.000 nhà quản lý hàng đầu của mình. Thông điệp được lãnh đạo $\mathrm{BP}$ chia sẻ rất rõ ràng: Công ty công nghệ kỹ thuật số và các quy trình công việc mới phải được bổ sung, điều này có thể tiết kiệm hàng tỷ USD và có thêm nhiều cơ hội kinh doanh mới. Kết hợp 2 yếu tố này đã có tác động đặc biệt đến các dự án ngoài khơi của $\mathrm{BP}$, nơi $\mathrm{BP}$ đang tìm kiếm nguồn trữ lượng bổ sung trong khi nỗ lực giảm thời gian thi công. Đầu năm 2019, BP đã hoàn thành việc lập kế hoạch và khoan 1 giếng nước sâu ở vịnh Mexico trong 13 tuần, chỉ bằng một nửa thời gian so với phương pháp thông thường. Cải thiện cách quản lý chuỗi cung ứng đã tiết kiệm cho BP khoảng 230.000 USD trong khoảng thời gian 3 tuần trên giàn Mad Dog ở vịnh Mexico.

BP đầu tư cho các doanh nghiệp khởi nghiệp (startups): Kể từ khi thành lập, BP đã đầu tư nửa tỷ USD cho các nhà phát triển công nghệ khởi nghiệp. Cuối năm 2018, các giám đốc điều hành đã "bật đèn xanh" để tạo ra vườn ươm công nghệ đầu tiên của $\mathrm{BP}$. $\mathrm{BP}$ đã đầu tư 20 triệu USD vào Beyond Limits để nghiên cứu điện toán nhận thức (cognitive computing) có thể giúp quản lý hoạt động các giếng khoan. Thử nghiệm lớn đầu tiên sử dụng điện toán nhận thức trong quá trình xử lý hiện tượng xuất hiện cát trong quá trình khai thác dầu (sand production) đã được tiến hành tại một dự án của BP ở Azerbaijan. Sử dụng công nghệ mới này để phát hiện hiện tượng xuất hiện cát trong quá trình khai thác dầu và hiện tượng rò rỉ trong giếng, BP đã tiết kiệm được 100 triệu USD chi phí [17].

\subsubsection{ENI}

ENI xây dựng Chương trình chuyển đổi số với các mục tiêu cụ thể [18]:

- An toàn và tính toàn vẹn của tài sản cải thiện sự an toàn của người lao động; tăng tính toàn vẹn và an ninh bảo mật tài sản.

- Nâng cao hiệu quả hoạt động sản xuất và thương mại: tối ưu hóa sản xuất và tăng hiệu quả hoạt động trong toàn bộ chuỗi giá trị bằng cách áp dụng rộng rãi các giải pháp kỹ thuật số; cải thiện hoạt động kinh doanh bán lẻ, hoạt động thương mại và mở rộng căn cứ khách hàng (customer base); cải thiện các quy trình nội bộ thông qua việc phân tích các giải pháp kỹ thuật số để hỗ trợ các quy trình.

- Giảm phát thải carbon và nền kinh tế tuần hoàn (circular economy): Giảm phát thải carbon liên tục của các hoạt động thông qua việc sử dụng các thuật toán dự đoán cho phép giảm lượng khí thải $\mathrm{CO}_{2}$, tối đa hóa hiệu quả năng lượng và giảm hiện tượng đốt bỏ khí; tìm kiếm 
các giải pháp kỹ thuật số để hỗ trợ chiến lược phát triển nền kinh tế tuần hoàn, tạo điều kiện và kích hoạt quá trình tái chế, giảm thiểu, tái sử dụng và chia sẻ tài nguyên.

- Đổi mới sáng tạo và tiềm năng con người: Hơn 50 sáng kiến đổi mới sáng tạo; các sáng kiến quản lý sự thay đổi hỗ trợ cho trụ sở chính và nhân viên công trường liên quan đến việc triển khai các sáng kiến kỹ thuật số.

ENI đang tham gia vào các lĩnh vực công nghệ kỹ thuật số:

- Học máy và trí tuệ nhân tạo: Giảm thiểu rủi ro thăm dò và gia tăng trữ lượng; giảm thời gian không sản xuất trong khi khoan (non productive time) và tăng hiệu quả điều hành khoan; phát triển dự án thông qua số hóa các tiêu chuẩn kỹ thuật; sử dụng Al trong suốt chuỗi giá trị cho đến bán lẻ để phát triển hệ thống thiết lập động giá sản phẩm tại các trạm dịch vụ.

- Chuỗi khối: Kinh doanh và vận chuyển dầu thô và các ứng dụng cho các quy trình kinh doanh nội bộ.

- Thực tế ảo (virtual reality): Các ứng dụng để hỗ trợ đào tạo an toàn, với kịch bản tai nạn và mô phỏng giàn khoan ảo.

- Thực tế tăng cường (augmented reality): Sử dụng các máy tính bảng và điện thoại thông minh để đơn giản hóa và nâng cao hiệu quả hoạt động của hệ thống, cải thiện sự an toàn khi vận hành.

- Robot và thiết bị bay không người UAV tiên tiến (Drone): Ứng dụng robot và UAV để làm cho các hoạt động kiểm tra, phát hiện, giám sát và bảo trì nhà máy, công trình hiệu quả hơn, đặc biệt là ở các khu vực trên cao.

- loT và cảm biến: Các ứng dụng để tăng công suất nhà máy công nghiệp để cung cấp nhiều hơn và đầy đủ hơn các dữ liệu và sử dụng để bảo trì và tối ưu hóa sản xuất, cho đến ứng dụng thiết bị đeo thông minh (huy hiệu thông minh, mũ bảo hiểm thông minh) nhằm tăng cường an toàn cá nhân.
Các dự án chuyển đổi số của Eni: Eni đã triển khai nhiều dự án chuyển đổi số ở các cơ sở của doanh nghiệp như: Trung tâm kỹ thuật số tại trụ sở tại Milan với 140 dự án kỹ thuật số với khoảng 1.300 người tham gia trong giai đoạn 2019 - 2022; Chương trình Digital Lighthouse tại 11 địa điểm ở Ý; Trung tâm Dũ liệu Xanh - Siêu máy tính HPC5 ở Ferrera với sức manh tính toán nằm trong top 17 thế giới về dữ liệu lớn và phân tích; EniPower an toàn thông minh để đảm bảo an toàn tối đa cho người vận hành; số hóa mảng bán lẻ và di động thông minh; các dụ án Digital Lighthouse - dự án chuyển đổi kỹ thuật số nhà máy lọc dầu; phân tích nâng cao và dữ liệu lớn để phát triển các thuật toán dự đoán và cải thiện tính toàn vẹn của tài sản; an toàn thông minh và nhà điều hành nâng cao để đảm bảo an toàn tối đa cho người vận hành; sử dụng nguyên mẫu thực tế ảo để đào tạo an toàn.

Các khoản đầu tư cho chuyển đổi số trong năm 2019: 105 triệu EUR đầu tư vào chuyển đổi kỹ thuật số; 173 triệu EUR lợi ích kinh tế được tạo ra trong năm 2019.

\subsubsection{Total}

Để đẩy nhanh tiến trình chuyển đổi số, Total xây dựng và đưa vào vận hành nhà máy kỹ thuật số (digital factory) rộng $5.500 \mathrm{~m}^{2}$ trong năm 2020. Khoảng 300 nhà phát triển (developers), nhà khoa học dữ liệu, kỹ sư kiến trúc số và chuyên gia kỹ thuật số để hợp tác với các chuyên gia của Total nhằm tận dụng khả năng của các công cụ kỹ thuật số, đưa ra các giải pháp sáng tạo kỹ thuật số để cải thiện và phát triển hơn nữa các hoạt động kinh doanh của Total, đặc biệt là lĩnh vực quản lý và kiểm soát tiêu thụ năng lượng, năng lượng mới và giảm tác động môi trường. Tham vọng của Total là tạo ra giá trị bổ sung 1,5 tỷ USD/năm vào năm 2025 và giảm chi phí hoạt động, đầu tư [19].

Nhà máy kỹ thuật số sẽ đóng vai trò là "máy gia tốc", cho phép Total triển khai một cách có hệ thống các giải pháp kỹ thuật số. Total mong muốn tích hợp các công nghệ trí tuệ nhân tạo, loT và $5 \mathrm{G}$ vào các

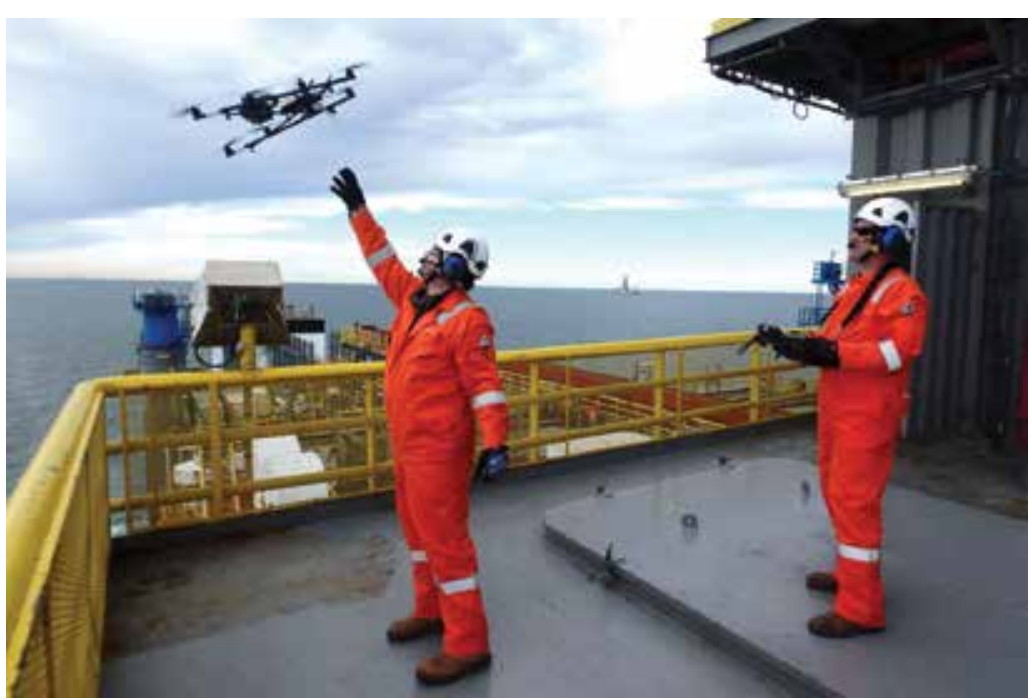

Hình 2. Thiết bị bay không người (drones) kiểm tra giàn khoan ngoài khoi vịnh Mexico năm 2011. Nguôn: The New York Times 
doanh nghiệp sớm nhất có thể. Nhà máy kỹ thuật số là bước tiến trong quy trình chuyển đổi số và sẽ thu hút tài năng mới cần thiết cho Total. Total đã ký thỏa thuận hợp tác với Google về trí tuệ nhân tạo, các khoa học trái đất và với Tata Consultancy Services về xây dựng nhà máy lọc dầu 4.0.

Total đưa vào sử dụng Siêu máy tính Pangea III: Năm 2019, Total đã đưa vào sử dụng siêu máy tính Pangea III mới, nhân công suất tính toán từ 5 - 31,7 petaflops (tương đương 170.000 máy tính xách tay kết hợp lại) và tăng gấp 3 dung lượng lưu trữ lên 76 petabyte (tương đương với khoảng 50 triệu bộ phim HD). Được phát triển bởi IBM, năng lực tính toán của Pangea III, bổ sung vào các phiên bản trước (Pangea I và II), hiện được xếp hạng siêu máy tính mạnh nhất số 1 trong ngành và là máy tính mạnh thứ 11 trên toàn cầu (xếp hạng TOP 500) [20].

Pangea III cho phép Total giảm rủi ro địa chất trong thăm dò và phát triển mỏ, đẩy nhanh tiến độ dự án và tăng giá trị tài sản thông qua việc tối ưu các hoạt động điều hành mỏ, tối ưu hóa chi phí. Pangea III có nhiều ứng dụng, đặc biệt trong 3 lĩnh vực khác nhau, gồm: i) Xử lý hình ảnh địa chấn trong thăm dò và phát triển mỏ dầu khí; ii) Mô hình phát triển và khai thác dầu khí; iii) Đánh giá và chọn lọc tài sản mỏ. Các khả năng nâng cao của Pangea III, cũng sẽ mở rộng sang các ứng dụng mới như tối ưu hóa các quy trình tinh chế hoặc cải thiện các đặc tính của dầu nhờn. Ngoài ra, Pangea III cho phép các nhóm nghiên cứu R\&D thử nghiệm các thuật toán mới phức tạp và tạo điều kiện phát triển các giải pháp trí tuệ nhân tạo, tiềm năng tăng trưởng quan trọng cho Total cùng với sự hợp tác với Google Cloud.

\subsubsection{Pertamina}

Đầu năm 2020, Pertamina ( Indonesia) đã trao cho Halliburton Hợp đồng chuyển đổi kỹ thuật số. Halliburton sẽ triển khai các ứng dụng kỹ thuật dầu khí của Pertamina trên đám mây iEnergy ${ }^{\oplus}$, dịch vụ đám mây lai (hybrid cloud) do Landmark - công ty con của Halliburton phát triển. Hệ thống đám mây iEnergy ${ }^{\circledR}$ giúp giảm chi phí cơ sở hạ tầng và nâng cao hiệu quả của việc tích hợp, quản lý và hỗ trợ dữ liệu giếng khoan giữa các đơn vị và công ty con của Pertamina [21].

Hợp đồng sẽ triển khai các ứng dụng gồm trí tuệ nhân tạo, học máy và phân tích dữ liệu để giải quyết các vấn đề thăm dò khai thác dầu khí và hỗ trợ các sáng kiến chuyển đổi kỹ thuật số của Pertamina. Các ứng dụng DecisionSpace ${ }^{\circledR} 365$ sẽ cho phép Pertamina hợp lý hóa quy trình làm việc trong quá trình thăm dò và khai thác, cải thiện hiệu suất khoan, nâng cao khả năng ra quyết định và tăng sản lượng khai thác. Hợp đồng này có thể mang lại hiệu quả cao hơn và tối đa hóa giá trị tài sản của Pertamina bằng cách tích hợp các ứng dụng và dữ liệu chạy trên đám mây iEnergy ${ }^{\oplus}$. Pertamina đã đặt nền tảng để tạo ra hiểu biết mới nhằm đẩy nhanh tiến trình chuyển đổi số.

\section{Chuyển đổi số trong thăm dò khai thác dầu khí ở Việt Nam}

\section{1. Áp dụng công nghệ số trong thăm dò khai thác dầu khí ở Việt Nam}

Các doanh nghiệp dầu khí hoạt động ở Việt Nam đã sử dụng các công nghệ số từ khá lâu, tuy nhiên chuyển đổi số hay áp dụng các công nghệ số đông bộ, hiện đại, tiên tiến hiện mới đang bắt đầu được chú ý nhiều hơn. Trí tuệ nhân tạo được sử dụng để phân tích thuộc tính địa chấn, minh giải tài liệu địa chấn (xác định hệ thống đứt gãy, mức độ nứt nẻ trong móng...), phân tích tài liệu địa vật lý giếng khoan để xác định tiềm năng dầu khí, tính chất của đá chứa đặc biệt là đá chứa trong móng (bề dày, độ rỗng, độ bão hòa dầu khí...); các công nghệ số trong thiết kế, thi công và điều hành khoan, hoàn thiện giếng; quản lý khai thác mỏ. Tuy nhiên, mức độ áp dụng và tính đồng bộ còn ở mức thấp.

Đối với công tác thăm dò, trong quá trình thi công các giếng khoan thăm dò, thẩm lượng, tài liệu giếng khoan từ giàn khoan ngoài khơi thường được mã hóa và chuyển về trung tâm dữ liệu, trung tâm xử lý trên đất liền qua internet. Một số nhà điều hành nhận tài liệu giếng khoan bằng cách truy cập cơ sở dữ liệu của các doanh nghiệp dịch vụ kỹ thuật lưu trên hệ thống lưu giữ đám mây.

Đối với công tác phát triển, khai thác mỏ, các nhà điều hành có hệ thống quản lý dữ liệu khai thác hay hệ thống thu thập, truyền dữ liệu công nghệ (Production Data Management System - PDMS); việc truyền dữ liệu tức thời (real time) của các giếng ở các mỏ ngoài khơi về đất liền sử dụng dịch vụ đường truyền do các doanh nghiệp viễn thông cung cấp. Các hệ thống PDMS thường sử dụng giải pháp quản lý điều hành mỏ tức thời (real time operation) của Schlumberger, Baker Hughes và Halliburton. Ngoài ra, các nhà điều hành đồng thời duy trì hệ thống báo cáo theo thời gian định kỳ gửi về các trung tâm dữ liệu, trung tâm điều hành trong đất liền qua email, internet. Khối lượng dữ liệu đặc biệt là dữ liệu khai thác ở các giếng, các mỏ rất lớn, vì vậy các nhà điều hành đều phải tiến hành 
lưu giữ (back up) tài liệu vào băng từ để định kỳ vận chuyển vào đất liền. Tuy nhiên, việc phân tích sử dụng tổng hợp khối lượng khổng lồ dữ liệu đa dạng của các mỏ để phục vụ cho công tác quản lý, điều hành mỏ còn ở mức độ khiêm tốn. Với sự phát triển nhanh và ngày càng mạnh mẽ của trí tuệ nhân tạo, phân tích dữ liệu lớn sẽ làm tăng lượng thông tin khai thác được từ dữ liệu thu thập, tăng hiệu quả sử dụng các dữ liệu thu được ở các mỏ.

Một số công trình dầu khí điển hình đã được áp dụng công nghệ số tiên tiến. Năm 2008, Hoàn Vũ JOC và PVEP đã đưa vào giàn đầu giếng không người (unmanned WHP) khai thác dầu ở mỏ Cá Ngừ Vàng, Lô 092; giàn được kết nối với giàn xử lý trung tâm CPP3 mỏ Bạch Hổ, Lô 09-1 của Vietsovpetro. Năm 2019, Liên doanh Việt - Nga “Vietsovpetro" đã đưa vào giàn nhẹ BK-20 khai thác dầu ở mỏ Bạch Hổ, Lô 09-1; giàn được

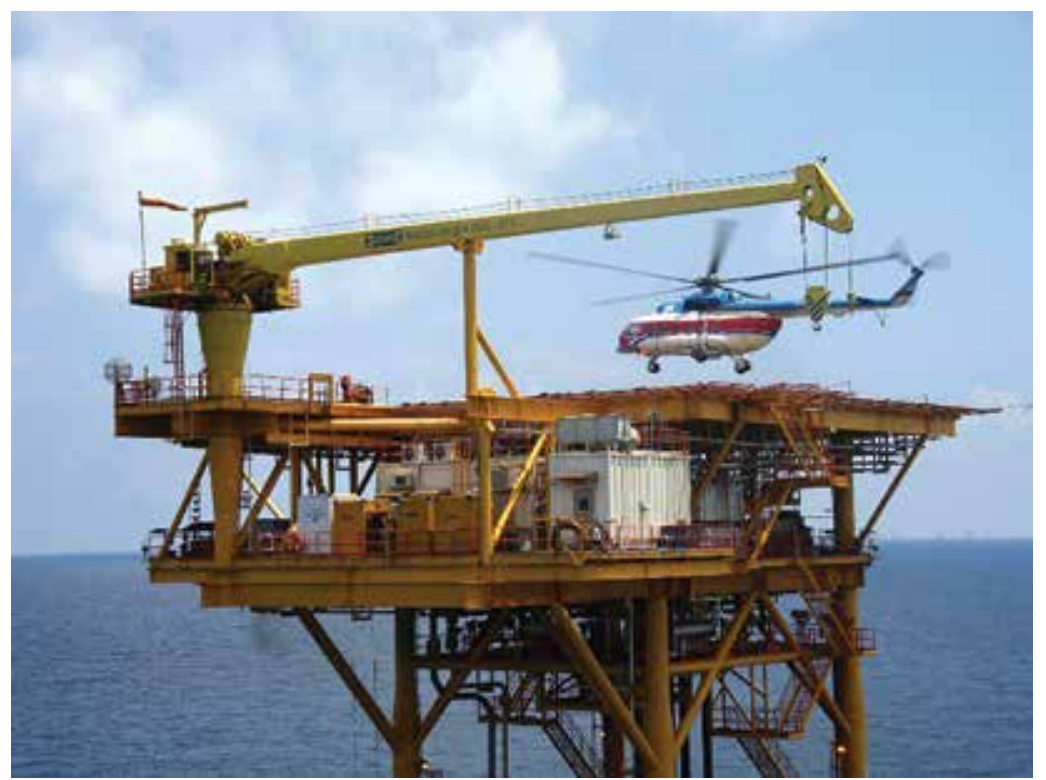

Hình 3. Giàn đâuu giếng không người (unmanned WHP) ở mỏ Cá Ngừ Vàng, Lô 09-2. Nguồn: Hoàn Vũ JOC

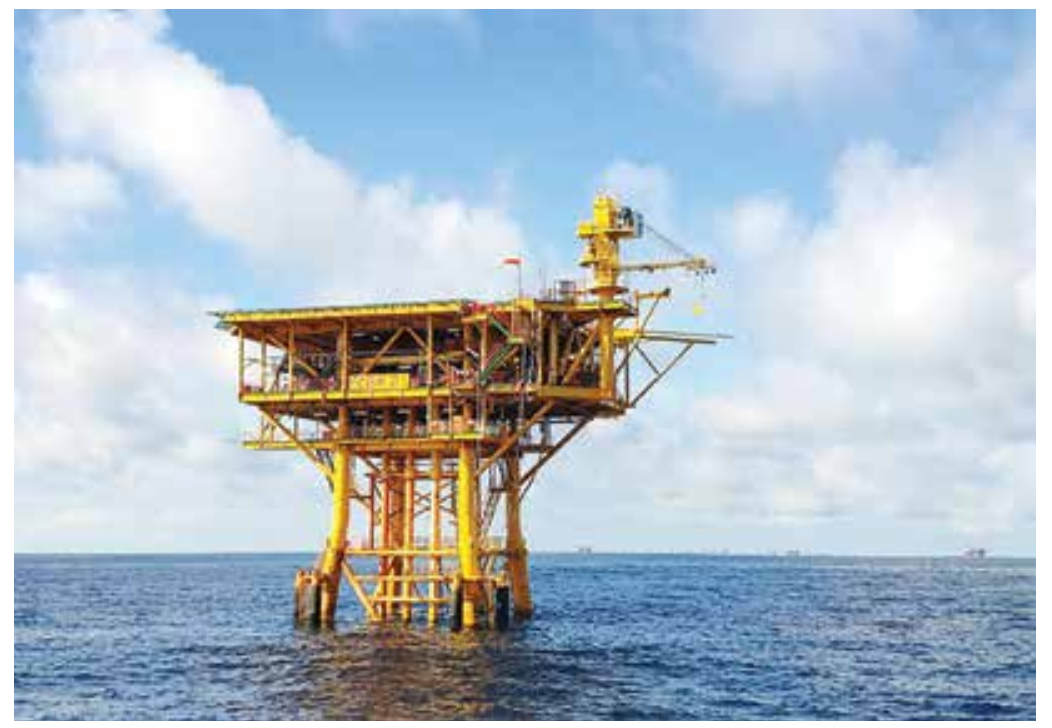

Hình 4. Giàn nhe không người (unmanned platform) BK-21 ở mỏ Bạch Hổ, Lô 09-1. Nguôn: Vietsovpetro thiết kế dưới dạng giàn đầu giếng không người (unmanned), được điều khiển từ xa từ giàn xử lý trung tâm CPP3 mỏ Bạch Hổ. Tiếp đó, ngày 2/10/2020 Vietsovpetro đã hoàn thành và đưa vào khai thác dầu giàn BK-21 tại mỏ Bạch Hổ. Đây là giàn mini BK không người ở thế hệ mới của Vietsovpetro với 9 lỗ khoan và được điều khiển từ xa từ giàn mẹ MSP6; công trình được Viện NIPI nghiên cứu, thiết kế phục vụ cho Vietsovpetro phát triển các mỏ nhỏ, mỏ cận biên, đã được tối ưu hóa về thiết kế, chi phí xây dựng và chi phí vận hành. Vietsovpetro dự kiến triển khai dự án thí điểm áp dụng "Bản sao kỹ thuật số Digital Twin" cho giàn không người BK-20 mỏ Bạch Hổ.

Đối với công tác nghiên cứu khoa học, Viện Dầu khí Việt Nam (VPI) đã đẩy mạnh công tác chuyển đổi số trong doanh nghiệp, tiến tới quản lý số và hoạt động kinh tế số, từng bước hoàn thiện môi trường doanh nghiệp tốt nhất cho đổi mới sáng tạo. Các dữ liệu không thuộc danh mục tài liệu mật đều được số hóa và lưu trữ trên SharePoint Online và Onedrive. Việc dữ liệu được số hóa và lưu trữ trên nền tảng đám mây cho phép người dùng dễ dàng quản lý dữ liệu, truy cập mọi lúc mọi nơi và tránh được rủi ro mất dữ liệu, cung cấp khả năng khôi phục thông tin/dữ liệu đã xóa bỏ khi có nhu cầu. VPI áp dụng Power Business Intelligence - Power BI trong phân tích số liệu nghiên cứu khoa học, phân tích dữ liệu hoạt động điều hành. VPI cũng đã áp dụng trí tuệ nhân tạo trong phân tích, minh giải tài liệu địa chấn, địa vật lý giếng khoan để xác định tiềm năng dầu khí, tính chất các vỉa chứa; các công nghệ số trong thiết kế, thi công và điều hành khoan, hoàn thiện giếng để thực hiện các đề tài nghiên cứu khoa học. VPI đang thử nghiệm sử dụng công nghệ học máy, công nghệ về trí tuệ nhân tạo để tập hợp, khai thác hiệu quả cơ sở dữ liệu.

Từ năm 2019, Trường Đại học Dầu khí Việt Nam (PVU) triển khai thực hiện nhiệm vụ khoa học công nghệ "Nghiên cứu xây dựng hệ thống trí tuệ nhân tạo tích hợp cơ sở dữ liệu địa chất dầu khí để đánh giá triển 
vọng dầu khí" thuộc Chương trình khoa học và công nghệ trọng điểm cấp quốc gia giai đoạn đến năm 2025 “Hỗ trợ nghiên cứu, phát triển và ứng dụng công nghệ của công nghiệp 4.0" (Chương trình KC-4.0/19-25 do Bộ Khoa học và Công nghệ quản lý). Nội dung chính của nhiệm vụ này là nghiên cứu, xây dựng các thuật toán, phần mềm trí tuệ nhân tạo hiện đại có khả năng phân tích dữ liệu lớn để phân loại, nhận dạng, xác định chính xác các bộ tiêu chí và dấu hiệu triển vọng dầu khí; ứng dụng thử nghiệm tại khu vực phía Bắc bể Sông Hồng.

\subsection{Một số khó khăn, rào cản đối với công tác chuyển đổi số trong thăm dò khai thác dâu khí ở Việt Nam}

- Các khó khăn, rào cản chung của quốc gia

+ Hạ tầng viễn thông đã được phát triển nhanh, tạo nền tảng cho phát triển kinh tế - xã hội, đặc biệt trong thời đại số. Cụ thể, hạ tầng viễn thông đã phủ rộng khắp toàn quốc hơn $600.000 \mathrm{~km}$ cáp quang, với tốc độ truy nhập cao (đạt > $27 \mathrm{MBps}$ ). Số thuê bao băng rộng cố định hơn 13 triệu (trong đó hơn 12 triệu thuê bao sử dụng cáp quang FTTx, tốc độ truy cập hơn $10 \mathrm{MBps}$ ). Tổng băng thông quốc tế đạt hơn 8,1 TBps. Mạng di động phát triển, tỷ lệ phủ sóng đạt 99,7\%. Mạng di động $5 \mathrm{G}$ đã được cấp phép thử nghiệm, khi triển khai sẽ là bước đột phá về tốc độ kết nối, là nền tảng quan trọng kết nối hạ tầng loT trong chuyển đổi số [2]. Mạng viễn thông cần đi trước một bước trong chuẩn bị hạ tầng cho chuyển đổi số. Để tạo điều kiện cho chuyển số thời gian tới cần tiếp tục phát triển hạ tầng số, đặc biệt là sớm triển khai chính thức mạng di động $5 G$, đồng thời phải quan tâm bảo đảm an toàn an ninh thông tin. Vấn đề bảo vệ dữ liệu và an ninh mạng vẫn là thách thức lớn mà Việt Nam phải đối mặt.

+ Môi trường pháp lý cho phát triển ICT: Trong thời gian qua, các văn bản pháp lý đã được ban hành tạo điều kiện ứng dụng và phát triển ICT trong các lĩnh vực như Luật Công nghệ thông tin, Luật An toàn thông tin mạng, Luật An ninh mạng, các nghị định... Tuy nhiên, việc xây dựng môi trường pháp lý hiện nay vẫn rất chậm, chưa theo kịp nhu cầu xã hội, đặc biệt trong các lĩnh vực mới khi thực hiện chuyển đổi số. Cụ thể như thiếu hành lang pháp lý cho phát triển kinh tế chia sẻ; chia sẻ, mở dữ liệu của cơ quan chính phủ, của doanh nghiệp; bảo vệ dữ liệu cá nhân, thông tin riêng tư; vấn đề quyền, đạo đức khi ứng dụng trí tuệ nhân tạo... Điều này gây cản trở rất lớn cho quá trình chuyển đổi số.

- Các khó khăn, rào cản nội tại của ngành dầu khí
Tập đoàn Dầu khí Việt Nam có 4 đơn vị/chi nhánh/liên doanh hoạt động trong lĩnh vực thăm dò khai thác dầu khí là: Tổng công ty Thăm dò Khai thác Dâu khí (PVEP), Liên doanh Việt - Nga "Vietsovpetro", Công ty Điều hành Dầu khí Biển Đông (Bien Dong $\mathrm{POC}$ ) và Công ty Điều hành Dầu khí Phú Quốc (Phu Quoc POC). PVEP là nhà điều hành một số lô đang trong giai đoạn tìm kiếm thăm dò và chỉ điều hành một số ít mỏ dầu với sản lượng không nhiều, cụ thể: trực tiếp điều hành mỏ Đại Hùng (Lô 05-1a), điều hành thay PVN/Nhà nước các mỏ Thăng Long - Đông Đô (Lô 01/97 \& 02/97), Ruby, Diamond, Pearl, Topaz (Lô 01/17 \& 02/17), Sông Đốc (Lô 46/13). Vietsovpetro đang điều hành khai thác các mỏ dầu Bạch Hổ, Rồng, Gấu Trắng, Thỏ Trắng (Lô 09-1), Nam Rồng - Đồi Mồi (Lô 09-1 \& 09-3), Cá Tầm (093/12), mỏ khí Thiên Úng (Lô 04-3) và một số lô đang trong giai đoạn tìm kiếm thăm dò. Bien Dong $P O C$ đang điều hành khai thác cụm mỏ khí Hải Thạch - Mộc Tinh (Lô 05-2 \& 05-3). Phu Quoc POC đang điều hành phát triển cụm mỏ khí Kim Long - Ác Quỷ - Cá Voi (ở các Lô B, 48/95 và 52/97). Nhìn chung, mức độ số hóa của ngành dầu khí nói chung và lĩnh vực thăm dò khai thác dầu khí nói riêng chưa theo kịp xu thế chuyển đổi số của ngành dầu khí cũng như các ngành công nghiệp khác trên thế giới.

+ Các mỏ đang khai thác đa số là mỏ nhỏ trừ các mỏ của Vietsovpetro ở Lô 09-1, các mỏ của Công ty Liên doanh Điều hành Cửu Long (Cuu Long JOC) ở Lô 15-1, khối lượng dữ liệu khác nhau được các công ty điều hành quản lý riêng biệt.

+ Hệ thống phần cứng, phần mềm sử dụng trong thăm dò khai thác dầu khí ở các đơn vị, công ty dầu khí khác nhau.

+ Trong bối cảnh chuyển đổi số, dữ liệu số đóng vai trò rất quan trọng, là tài sản, tài nguyên, điều kiện tiên quyết cho chuyển đổi số. Cơ sở dữ liệu thăm dò khai thác dầu khí đã được đề nghị xây dựng từ lâu nhưng do vướng mắc cơ chế, chính sách và thiếu tính quyết liệt nên đến nay vẫn chưa có cơ sở dữ liệu thăm dò khai thác dầu khí tổng thể, đồng bộ. Mỗi đơn vị (PVEP, Vietsovpetro, VPI), công ty điều hành có hệ thống cơ sở dữ liệu (mức thấp) riêng biệt, không thống nhất. Việc kết nối, chia sẻ, mở các cơ sở dữ liệu giữa PVN và các đơn vị, giữa các đơn vị với nhau rất hạn chế, chủ yếu là cát cứ thông tin; điêu này làm lãng phí nguồn lực, cản trở triển khai ứng dụng và phát triển công nghệ số.

+ Lực lượng lao động có chuyên môn công nghệ thông tin trong thăm dò khai thác dầu khí có kiến thức, kỹ năng công nghệ cao (đặc biệt là về công nghệ số) chiếm 
tỷ lệ rất ít; cán bộ kỹ thuật thăm dò khai thác dầu khí chưa được cập nhật thường xuyên về công nghệ số, kỹ năng làm việc với các trang thiết bị sử dụng công nghệ số.

\section{3. Đề xuất chuyển đổi số lĩnh vực thăm dò khai thác dâu khí}

Tại Diễn đàn Kinh tế thế giới năm 2017, các khuyến nghị cho cả ngành dầu khí để thực hiện chuyển đổi số thành công đã được đề cập, bao gồm [4]:

- Đặt ưu tiên kỹ thuật số cho các giám đốc điều hành cấp cao, xây dựng lộ trình chiến lược kỹ thuật số: Chuyển đổi số cần phải được ủng hộ từ lãnh đạo cấp cao. Điều này bao gồm thiết lập tầm nhìn rõ ràng, cam kết tài trợ và nguồn lực và nỗ lực thay đổi quản trị liên quan đến chuyển đổi số. Các chiến lược kỹ thuật số hỗ trợ chiến lược tổng thể cần đảm bảo kỹ thuật số được tích hợp hoàn toàn vào lĩnh vực kinh doanh cốt lõi của doanh nghiệp.

- Thúc đẩy văn hóa sáng tạo và đổi mới công nghệ: Cần cởi mở với các ý tưởng và cách thức làm việc mới.

- Đầu tư vào nguồn nhân lực và các chương trình phát triển thúc đẩy tư duy mới, tư duy kỹ thuật số, phát triển lực lượng lao động số: Xây dựng một lực lượng lao động am hiểu kỹ thuật số, vừa là lực lượng nền tảng vừa là động lực chính để tối đa hóa việc nắm bắt được các giá trị của chuyển đổi số. Cập nhật chương trình đào tạo, bảo đảm điều kiện cơ sở vật chất đào tạo kiến thức, kỹ năng số từ lãnh đạo đến tất cả nhân viên; tạo hệ sinh thái để hỗ trợ người lao động trong việc đào tạo lại và đào tạo nâng cao trong suốt cuộc đời; hạn chế chảy máu chất xám, thu hút nhân tài là các chuyên gia công nghệ thông tin trình độ cao.

- Tiếp tục phát triển khả năng áp dụng kỹ thuật số thông qua đầu tư, xây dựng, mua hoặc hợp tác với các đối tác: Đưa ra cách tiếp cận để phát triển các khả năng mới thu nhận được trong quá trình chuyển đổi số. Điều này bao gồm các quyết định về việc xây dựng, áp dụng phương pháp quản trị phù hợp để mở rộng quy mô công nghệ và nền tảng kỹ thuật số.

- Cải cách cấu trúc dữ liệu, tối ưu hóa việc sử dụng các nền tảng dữ liệu (data platform): Dữ liệu đóng vai trò trung tâm của chuyển đổi kỹ thuật số, vì vậy sự hài hòa, khả năng tích hợp và tương tác của các nền tảng dữ liệu là rất quan trọng.

- Đầu tư vào hệ sinh thái hợp tác qua việc sử dụng quan hệ đối tác và nền tảng hoạt động trong môi trường kinh tế chia sẻ: Xác định các cơ hội để tăng cường hợp tác và hiểu biết về các nền tảng kinh tế chia sẻ (sharingeconomy platforms). Điều này sẽ cho phép vượt qua cạm bẫy tiềm ẩn do sự thay đổi sở thích của khách hàng trong quá trình phát triển của nền kinh tế chia sẻ.

Với các đặc điểm của công tác thăm dò khai thác dầu khí ở Việt Nam, cần sớm nghiên cứu, đánh giá, xây dựng kế hoạch tổng thể chuyển đổi số lính vực thăm dò khai thác dầu khí với mục tiêu cụ thể cho từng giai đoạn, lộ trình, bước đi phù hợp cho từng chủ thể tham gia vào quá trình chuyển đổi số từ các công ty điều hành/các nhà thầu dầu khí, các đơn vị thành viên, viện nghiên cứu, các ban liên quan của Tập đoàn. Trước mắt, có thể xem xét, tập trung giải quyết một số vấn đề:

+ Tim kiếm tư vấn chuyên nghiệp để phối hợp đánh giá chi tiết hiện trạng áp dụng công nghệ số, nhu cầu chuyển đổi số ở PVN, các đơn vị thành viên, các công ty điều hành dầu khí, xây dựng chương trình chuyển đổi số lĩnh vực thăm dò khai thác dầu khí với mục tiêu cụ thể cho từng giai đoạn. Cần lưu ý rằng, quá trình chuyển đổi số phức tạp, diễn ra lâu dài, đòi hỏi nguồn kinh phí lớn; phải có sự tham gia và hợp tác của các "chủ mỏ", các nhà điều hành. Các hợp đồng dầu khí có thời hạn hiệu lực, tình trạng hoạt động khác nhau, một số hợp đồng dầu khí đang trong giai đoạn cuối nên cần có các đánh giá chi tiết làm cơ sở thuyết phục các "chủ mỏ", các nhà điều hành tham gia thực hiện chuyển đổi số.

+ Nhanh chóng xây dựng cơ sở dữ liệu thăm dò khai thác dầu khí của từng lĩnh vực chuyên môn cụ thể và của toàn ngành.

+ Tăng cường công tác nghiên cứu, phát triển, áp dụng các công nghệ số, tự động hóa, trí tuệ nhân tạo và học máy, phân tích dữ liệu lớn, điện toán đám mây để nâng cao hiệu quả công tác thăm dò khai thác dầu khí. Trước hết cần xem xét, lựa chọn một số khâu có thể đẩy mạnh nghiên cứu, phát triển các nội dung trên như xử lý, minh giải tài liệu địa chấn, tài liệu địa vật lý giếng khoan, đánh giá đặc điểm vỉa chứa, tiềm năng dầu khí; lập kế hoạch/chương trình khoan, thiết kế giếng khoan, theo dõi và điều hành công tác khoan, hoàn thiện giếng; quản lý, điều hành khai thác mỏ.

+ Tăng cường công tác đào tạo, đào tạo lại, phổ cập kiến thức mới kịp thời cho lãnh đạo, cán bộ các cấp và nhân viên về công nghệ số, tự động hóa, trí tuệ nhân tạo và học máy, phân tích dữ liệu lớn, điện toán đám mây và các ứng dụng cụ thể trong thăm dò khai thác dầu khí. 


\section{Kết luận}

Chính phủ đã phê duyệt "Chương trình Chuyển đổi số quốc gia đến năm 2025, định hướng đến năm 2030" với mục tiêu kép là vừa phát triển Chính phủ số, kinh tế số, xã hội số, vừa hình thành các doanh nghiệp công nghệ số Việt Nam có năng lực đi ra toàn cầu [1]. Thông qua việc thực hiện chuyển đổi số, áp dụng nhiều hơn các nền tảng và ứng dụng kỹ thuật số, cùng với dữ liệu khai thác được tạo ra từ cơ sở hạ tầng hiện có, các doanh nghiệp dầu khí sẽ có cơ hội tốt hơn để vượt qua thách thức hiện tại và kích hoạt khả năng hoạt động từ xa, giúp ngành Dâuu khí Việt Nam tiếp tục phát triển.

Chuyển đổi số là công việc quan trọng, thiết thực, tuy nhiên quá trình này phức tạp, diễn ra lâu dài, đòi hỏi quyết tâm của lãnh đạo, nhân viên, cần có tư vấn chuyên nghiệp và nguồn kinh phí lớn. Việc chuyển đổi số trong lĩnh vực thăm dò, khai thác dầu khí đã và đang được thực hiện tại các đơn vị trong ngành Dầu khí Việt Nam, tuy nhiên còn "manh mún" và ở các mức độ khác nhau. Thăm dò khai thác dầu khí là lĩnh vực sản xuất kinh doanh cốt lõi của PVN, vì vậy cần sớm nghiên cứu, đánh giá, xây dựng kế hoạch tổng thể chuyển đổi số lînh vực thăm dò khai thác dầu khí với mục tiêu cụ thể cho từng giai đoạn, lộ trình, bước đi phù hợp.

\section{Tài liệu tham khảo}

[1] Thủ tướng Chính phủ, Phê duyệt "Chương trình Chuyển đổi số quốc gia đến năm 2025, định hướng đến năm 2030", Quyết định số 749/QĐ-TTg, 3/6/2020.

[2] Bộ Thông tin và Truyền thông, "Dự thảo Đề án chuyển đổi số quốc gia", 2019.

[3] Dxc.Technology and The Economist Intelligence Unit,"2019:Theyear of digital decisions".[Online]. Available: https://assets 1.dxc.technology/digital_transformation/ downloads/Digital_Decisions_Survey_Report.pdf.

[4] World Economic Forum, "Digital transformation initiative, oil and gas industry", 1/2017. [Online]. Available: https://reports.weforum.org/digital-transformation/wpcontent/blogs.dir/94/mp/files/pages/files/dti-oil-andgas-industry-white-paper.pdf.

[5] Andrew Trice, "The future of cognitive computing", 23/11/2015. [Online]. Available: https://www.ibm.com/ blogs/cloud-archive/2015/11/future-of-cognitivecomputing/.

[6] Accenture, "The 2016 upstream oil and gas digital trends survey". [Online]. Available: https://www.accenture. com/ch-en/insight-2016-upstream-oil-gas-digital-trendssurvey.

[7] Tech Target, "Definition: Internet of Things (IoT)". [Online]. Available: http://internetofthingsagenda. techtarget.com/definition/Internet-of-Things-loT.

[8] Çağlayan Arkan, "From disruption to opportunity: How digital is transforming the future of oil and gas", 4/9/2018.[Online].Available:https://cloudblogs.microsoft. com/industry-blog/manufacturing/2018/09/04/fromdisruption-to-opportunity-how-digital-is-transformingthe-future-of-oil-and-gas/.

[9] Oliver Wyman, "Upstream digital transformations - Will your digital portfolio of initiatives be enough?". [Online]. Available: https://www.mmc.com/content/dam/ mmc-web/insights/publications/2019/aug/UpstreamDigital-Transformations-FINAL-v2.pdf.

[10] Equinor, "Digitalisation is changing our company". [Online]. Available: https://www.equinor.com/ en/how-and-why/digitalisation-in-our-dna.html.

[11] Equinor, "Digitalisation driving value creation", 22/5/2017. [Online]. Available: https://www.equinor.com/ en/news/digitalisation-driving-value-creation.html.

[12] Equinor, "Is this Norway's most digital workplace?". [Online]. Available: https://www.equinor. com/en/magazine/most-digital-workplace.html.

[13] Equinor, "Equinor is hosting Techstars Energy Accelerator", 31/1/2019. [Online]. Available: https://www. equinor.com/en/magazine/techstars-energy-accelerator. html.

[14] Mark Venables, "Change of culture reaps rewards for BP's digital transformation". [Online]. Available: https:// www.forbes.com/sites/markvenables/2019/01/31/ change-of-culture-reaps-rewards-for-bps-digitaltransformation/\#4f55c7f76199.

[15] BP, "Digital innovation". [Online]. Available: https://www.bp.com/en/global/corporate/what-we-do/ technology-at-bp/digital-innovation.html.

[16] Offshore Technology, "Exploring the impact of artificial intelligence on offshore oil and gas", 15/5/2019. [Online]. Available: https://www.offshore-technology. com/features/application-of-artificial-intelligence-in-oiland-gas-industry/.

[17] Trent Jacobs, "Digital transformation at BP is starting to add up to billions", 16/5/2019. [Online]. 
Available: $\quad$ https://pubs.spe.org/en/jpt/jpt-articledetail/?art=5495.

[18] ENI, "The digital transformation plan". [Online]. Available: https://www.eni.com/en-IT/operations/italydigital-transformation-plan.html.

[19] Total, “Digital factory: Total accelerates its digital transformation", 12/11/2019. [Online]. Available: https:// www.total.com/news/digital-factory-total-accelerates-itsdigital-transformation.
[20] Total, "Total's pangea III supercomputer ranked first in industry worldwide", 18/6/2019. [Online]. Available: https://www.total.com/media/news/press-releases/ totals-pangea-iii-supercomputer-ranked-first-industryworldwide.

[21] Halliburton, "Halliburton awarded digital transformation contract in Indonesia", 25/2/2020. [Online]. Available: https://www.halliburton.com/en-US/ news/press-releases/2020/halliburton-awarded-digitaltransformation-contract-in-indonesia.html.

\section{DIGITAL TRANSFORMATION IN PETROLEUM EXPLORATION AND PRODUCTION}

\section{Nguyen Anh Duc}

Vietnam Oil and Gas Group

Email: ducna@pvn.vn

\section{Summary}

Digital transformation is providing businesses with a great opportunity for creating and capturing value. The development of technologies such as cloud computing, social media and big data analytics is driving trends that offer enormous potential to the petroleum industry.

The article focuses on introducing digital transformation trends in the world, current status and trends of digital transformation in oil and gas companies in general and in petroleum exploration and production in particular. The article also gives some recommendations for digital transformation of the petroleum exploration and production sector in Vietnam.

Key words: Digital transformation, petroleum exploration and production, trend. 